\title{
NATUREZA E HOMEM NA FORMAÇÃO CULTURAL DA AMERICA CHAMADA LATINA
}

Manuel Diégues Júnior

Quando se verificou a descoberta e, em seguida, a colonização da América de hoje, encontraram-se, em seu território, populações que apresentavam os mais diversificados estágios culturais; umas, ainda possuindo o mais rude primitivismo: outras, mal conhecendo o fogo e a cerâmica; algumas, entretanto, de nivel já bastante adiantado, se levarmos em conta, sobretudo, o isolamento em que se encontravam. Estas últimas são as chamadas civilizações andinas, porque localizadas nos Andes, e conhecidas geralmente como incas; e as civilizações mesoamericanas, formadas pelos astecas, no México, e os maias, na América Central, sobretudo Guatemala, onde ainda hoje constituem número expressivo em sua população. Eram grupos indigenas já possuidores de conhecimentos técnicos relativamente avançados; e ainda de um nível intelectual altamente desenvolvido, por conhecimento matemático e de escrita. Aos maias, por exemplo, atribui-se a origem de uma das três formas de escrita, hoje conhecidas, que deles se irradiou alcançando as populações astecas.

Distinguiram-se ainda os maias pela atividade agrária e pelo uso de uma escrita bastante complexa, pois resta muito ainda o que nela decifrar; o que se traduziu refere-se particularmente aos signos para cómputo do tempo. Pelo conhecimento matemático realizavam cálculos astronomicos, conhecendo o movimento solar, e possuíam o conceito de abstração matemática, com o zero, que intervinha em seus cálculos. Tinham o sentido de perspectiva em seus afrescos. Trata-se assim. peło que se vê desta resumida informação, de populações de alto nivel cultural, inclusive com percepções científicas, nem sempre encont radas em outros povos da mesma época e do mesmo estágio.

As populações localizadas nos Andes Centrais, chamadas incas, possuíam alto conhecimento de agricultura e de criação (lhamas, alpacas, patos), com o que se fazia o abastecimento de sua população; conheciam o sistema decimal traduzido no quipu: uma série de cordões pendentes de um cordão principal que, por meio de nós, segundo seu tipo e posição, indicava as dezenas, centenas, milhares ou outros algarismos. Faziam cálculos através do ábaco. Empregavam grandes blocos de pedra bem talhada em sua arquitetura; pontes suspensas, estradas pavimentadas, balsas e canoas escavadas em tronco de árvore, canais de irrigação, diques e canalização de rios eram outros aspectos da tecnologia dessas populações. Trabalhos em cerâmica e em metalurgia, inclusive com o conhecimento de bronze, instrumentos musicais completavam, entre outros, o quadro de vida dessas populações andinas. 
Não menos expressivo era o desenvolvimento das populações astecas, no que é hoje o México. Conheciam o calendário e a escrita hieroglífica; atividades de ceramistas, de trabalhos em mosaico de turquesa ou de concha, de plumistas, de ourives e joalheiros, tecelões e fiandeiros, escultores em madeira, entre outros, distribuíam-se pelos diversos bairros em que se localizava a população citadina dos astecas. Construíram diques e preparavam com o cacau uma bebida chamada chocolatl, hoje universalizada com seu nome popular de origem nahua. Possuíam um calendário litúrgico paralelo ao calendário solar.

Foi com estas populações - indigenas diferenciados em diversos tipos de cultura, rudimentares e complexas, primitivas ou altamente adiantadas ${ }^{1}$ - que entrou em contacto a colonização ibérica, possuidora esta de um nível de conhecimentos não apenas culturais, mas também científicos, bastante desenvolvidos, tendo em vista o que já se divulgava nos fins do século XV e começos do XVI.

Espanhóis e portugueses, estes na parte sul-americana que é hoje o Brasil, aqueles no restante do continente, que foram de início os grandes colonizadores da América hoje conhecida como Latina, justamente pelas razões de sua formação, já eram senhores de técnicas avançadas, de navegação, de conhecimentos astronômicos, de cálculos e sobretudo de armas. Pois constituíram estas, por sua superioridade técnica, fator decisivo na conquista do território americano àqueles povos mais desenvolvidos e sobretudo a outros menos desenvolvidos, como os do Brasil, por exemplo; o nivel cultural destes, embora bastante diversificado, nem de longe se aproximava do que havia nas civilizações andinas ou mesoamericanas. Aquelas armas e doenças disseminadas, como varíola e outras, se tornaram responsáveis pelo desaparecimento quase completo daquelas culturas.

O que se verificou também no Brasil, com a ocupação portuguesa, embora as populações aqui encontradas fossem de nível inferior aos incas ou maias, e, por condições de insuficiência técnica, muito mais fáceis de contaminação ou de destruição. Entretanto, o colonizador não pôde esquivar-se de render-se ao contacto com as diferentes populaçōes indígenas, delas recebendo e incorporando no processo de adaptação ao meio valores que lhes eram próprios; na habitação, na alimentação, em técnicas, embora rudimentares, de pesca, ou de caça, em remédios, etc.

Tornou-se o Novo Mundo ambiente de um encontro cultural que, entre dois grupos, se distribuiu nas múltiplas facetas que cada um deles apresentava, face à própria diversificação interna. Deste choque cultural resultou um quadro novo, interpenetrando-se os elementos ibéricos e indígenas, de modo a se criarem elementos novos ou se absorverem pelo outro os oriundos de um dos grupos.

Quando falamos em ibérico ou ibéricos, na generalização de espanhóis e portugueses, estamos longe de admitir apresentassem eles, ou cada um deles em particular, uniformidade cultural, formação monoliticamente una. Ao contrário: tanto portugueses como espanhóis eram diversificados, possuidores de variados níveis de cultura e portadores de diferenciações de comportamento decorrentes de sua distribuição regional. ${ }^{2}$

Tornou-se importante, no ambiente americano, esse pluralismo ibérico, por isso que transmitiu variedade de conhecimentos e, com suas diferenças culturais regionais, pôde 
enriquecer a formação americana, inclusive influenciando em sua diversidade contemporânea.

Se costumes espanhóis foram modificados pela influência da cultura nativa, face à adaptação ao novo ambiente, também elementos visíveis de cultura ind igena persistiram; e ainda hoje, em alguns países - o caso do México, da Guatemala, do Peru, da Bolívia, por exemplo - muitas de suas caracteristicas nacionais são de procedência indígena; muitos dos valores predominantes em sua cultura são originariamente indigenas. Sem prejuizo, é evidente, do domínio da cultura ibérica, que se tornou o lastro sobre o qual as fundiram, se absorveram, se recriaram, e assim permaneceram.

Se falamos em outras é que ao mesmo tempo que se desenvolvia o processo de relacionamento indígena $\mathrm{x}$ ibérico, em algumas áreas a entrada do elemento negro-africano ${ }^{3}$ ia trazer um novo contributo para a formação cultural da região. Foi outra presença importante esta, a do africano que, trazido como escravo, fez penetrar valores de sua cultura neste quadro de relações, que já então se processava. Desde cedo, mal iniciado o processo de colonização, verifica-se a entrada de escravos negros, e isto tanto na área espanhola como na área portuguesa. Notícias há de que já por volta de 1501 ou mais acertadamente $1502^{4}$ eram introduzidos escravos no Hatti e em São Domingos. Outros carregamentos se dirigiram para a parte norte da América, e não apenas para a parte insular. Carlos V concedeu monopólio de comércio de escravos com as Antilhas, para a introdução de 4.000 negros por ano. Cortès, por sua vez, introduziu escravos negros no México.

No que é hoje a América do Sul não foi diferente o comércio negreiro. Desde cedo os colonizadores introduzem escravos: no Peru, principalmente na faixa costeira; no Chile quase exclusivamente, é certo, na região de mineração do Copiapó; na Tierra Firme, que são hoje a Venezuela e a Colômbia, onde se avolumaram com o correr do tempo, para os trabalhos de agricultura e de mineração; na região do Prata, sobretudo para a Colônia do Sacramento, registrando-se em 1693 referências ao tráfico negreiro em Buenos Aires; em Montevidéu onde os primeiros negros entrados eram procedentes de Angola. No Brasil, o português faz o comércio negreiro, trazendo escravos de diversas partes da África e que se distribuíram por quase todo o território brasileiro em trabalhos de agricultura, de mineração, domésticos, urbanos.

Embora não se conhecendo com absoluta exatidão o volume desse comércio, isto é, o número exato de escravos africanos entrados nas Américas, sabe-se, porém, que sua influência foi notável; também participaram, os africanos escravizados, do processo transculturativo, do que permanecem muitos de seus traços em nossa cultura contemporânea. E isto não apenas em suas práticas religiosas, mas ainda em alimentação, em danças, em cantos, em técnicas de trabalho - deles foi a introdução da batéia na mineração de ouro no Brasil - e ainda em convivência social, sobretudo com a participação na mestiçagem verificada.

Tudo indica ser verdadeira a generalização a que chegou Gilberto Freyre com base em observações registradas por numerosos autores acerca do indio americano em diferentes regiões: a de que a cultura indígena encontrada seria inferior à da maior parte das áreas de cultura africana de onde se importaram negros para as plantações americanas. $^{5}$ O que se poderia confirmar pelos estudos sobre culturas africanas, em 
particular os de Frobenius, ao caracterizar o alto nível das diferentes manifestações de cultura encontradas em regiões da Äfrica. ${ }^{6}$ Culturas, aliás, altamente diferenciadas, não se podendo falar em uma cultura africana ou em um Homo Afer.

Apesar do condicionamento a que estavam sujeitos, sem liberdade para expandir, nas Américas espanhola e portuguesa, todo o seu acervo cultural, e isto por sua situação de escravos, são evidentes, na cultura latino-americana contemporânea, marcas visíveis de influência africana, através de variados traços ou complexos em diferentes manifestações; se não se pode generalizar tal situação para toda a América, é fora de dúvida que tais marcas estão nítidas no Brasil, em Cuba, no México, na Venezuela, na Colômbia, no Panamá, no Peru, na Dominicana, no Uruguai, na Argentina, em Trinidad, para citar alguns exemplos apenas, sem esquecer o caso mais característico que é o Haiti.

Referindo-se de modo particular às manifestações de natureza musical, onde o elemento negro fixou indelevelmente sua influência, Luis Alberto Sanchez pôde sintetizar algumas delas entre as mais características: os candombes de Montevidéu e Buenos Aires, as cumbias panamenhas, o tango argentino, o maxixe brasileiro - a que podíamos acrescentar o frevo e o samba também brasileiros -, a conga, cubana, a zamacueca peruana.?

De uma maneira geral, o elemento africano influenciou a formação cultural americana. $\mathrm{O}$ que ampliou o processo transculturativo, resultando um padrão cultural que hoje consideramos latino-americano, e conseqüentemente não exclusivamente ibérico, ou indígena, ou africano. Mas um produto da "criatividade cultural", em que resultou o processo de transculturação dos três grandes grupos étnico-culturais na formação dos hoje países da região.

Se podemos considerar o conhecimento científico e o técnico como partes da cultura, considerada esta como o comportamento total do grupo, evidencia-se que desse encontro triangular era o ibérico cientificamente ou tecnicamente o mais desenvolvido. 0 que não exclui a existência de conhecimentos indígenas, por exemplo, no uso de vegetais como alimento ou como remédio ou como veneno. $\mathrm{O}$ caso da mandioca, ou do milho na alimentação, ambos os produtos incorporados à alimentação do ibérico, e pelo português levado o primeiro - a mandioca - ao consumo de africanos, onde hoje se inclui como alimento essencial em Angola. Do milho, registra o professor Orlando Ribeiro que sua introdução em Portugal constituiu uma verdadeira revolução, pelas transformações populacionais, de cultivo e de alimentação que produziu. ${ }^{8}$

$\mathrm{O}$ caso ainda do tabaco: sabe-se da repercussão que teve seu encontro na América indígena e sua conseqüente difusão na Europa. Dos chamados efeitos mágicos do tacabo, que, em grande parte, era para esse fim usado entre os indígenas - entre algumas tribos, ingerido pela boca, e em outras, na iniciação dos curandeiros da tribo, ingerido pelo nariz - passou-se ao seu uso civilizado em charutos, cigarros e cachimbos. Difusão que se alastrou por toda a Europa.

O caso também de vários vegetais conhecidos como remédios que se incorporaram depois ao uso caseiro das populações rurais, incluindo-se entre os valores que poderíamos chamar civilizados para contrastar com sua presença na cultura popular. O caso igualmente do curare, conhecido pelos indígenas no Alto Amazonas como anestésico ou, 
pelo menos - a exemplo de outros vegetais - para envenenar as flechas e facilitar a caça à distância. Do curare, os excelentes estudos já divulgados pelas pesquisas de Paulo Carneiro e pelas informações de vários autores permitem mostrar a transição do seu uso entre os ind ígenas para usos hoje consagrados na medicina. ${ }^{9}$

Ao lado desse exemplo - o do aproveitamento atual do curare indigena pela ciência - podemos ainda assinalar que, no relacionamento entre os dominadores ibéricos e as populações indigenas, muitos valores oriundos das técnicas destas últimas se incorporaram aos padrões de vida dos colonizadores. E certo que possuíam estes uma tecnologia mais avançada que a dos nativos; e por isso mesmo sua inferioridade numérica pôde sobrepor-se à superioridade também numérica dos nativos. Mas mesmo nesta tecnologia é de convir que o elemento local pôde persistir em muitos aspectos. Em primeiro lugar, por sua adaptação ao meio, ou seja, pela sua incorporação já experimentada às condições do ambiente.

Técnicas de pesca ou de caça, por exemplo: tanto espanhóis como portugueses aceitaram e incorporaram aos hábitos de vivência na terra técnicas que os indígenas usavam para pesca ou para caça. Vários instrumentos ainda hoje persistentes na cultura latino-americana, para essas atividades, são de origem indígena. O que não faz esquecer que se implantaram, e ainda hoje se conservam, também técnicas ou instrumentos trazidos pelos dominadores. Da pesca, pequenos tipos de redes, anzóis de osso, envenenamento da água com plantas, arco e flecha, colocação de barragens ou tapagens são algumas dessas técnicas indigenas ainda em uso. $\mathrm{Na}$ caça de pequenos animais ou de pássaros igualmente se incorporaram técnicas, como o mundéu, o alçapão, a armadilha, todos elementos oriundos da tecnologia, tecnologia evidentemente ainda bastante primitiva, do indígena.

Nas técnicas agrícolas, talvez mais que em outros campos, pelo adiantamento cultural dos ibéricos, houve, sem dúvida, maior predominância do elemento introduzido. Aquelas técnicas, que eram usadas na Europa para os produtos também europeus, passaram a utilizar-se no cultivo das plantas nativas: da mandioca, do milho, do feijão. No caso da mandioca, por exemplo, sabe-se que no Brasil o português substituiu o tipiti indígena - instrumento de palha ou de trançado que servia para fazer extrair o suco venenoso da planta - pela prensa, técnica já adotada em Portugal para espremer vários produtos, inclusive a uva para o preparo do vinho.

Não há dúvida de que o primeiro contacto, pela violência com que se verificou, ${ }^{10}$ provocou a destruição não apenas de populações indígenas, se não ainda e principalmente de cultivos, de técnicas, de conhecimentos que naturalmente teriam sido úteis aos dominadores. Milho, mandioca, feijão, batata tiveram seus cultivos destruídos; era, sem dúvida, uma maneira de fazer com que os indígenas não pudessem subsistir pela carência de alimentos. No Peru, particularmente, a cultura incaica viu desaparecerem suas experiências de irrigação, de terraços agrícolas, de técnicas de cultivo da terra.

Mas embora destruindo-as, nestes primeiros contactos, tiveram os dominadores de posteriormente adaptar-se a elas, estabelecendo como çue um modus vivendi com os nativos. Dai é que começou a resultar o processo transculturativo: as duas culturas - a ibérica e a indígena - se interpenetrando, fusionando-se ou absorvendo-se em elementos ou valores fundamentais; foi possivel assim fazer surgir um quadro novo, sem prejuízo da 
conservação de muitos desses valores indígenas e da introdução de muitos dos valores trazidos pelo colonizador europeu.

Na realidade, não houve uma dominação cultural absoluta; ao contrário: verificou-se antes uma fusão. Tivemos assim, na formação do que é hoje a nossa cultura, de modo especial a cultura popular, mais um processo de transculturação, no sentido usado por Fernando Ortiz e aceito por autores contemporâneos - o caso de Malinowski - do que um processo de absorção da cultura tecnicamente inferior pela cultura tecnicamente superior.

Fernando Ortiz considera a expressão transculturação mais apropriada para definir o processo de transição de uma cultura a outra, com suas respectivas repercussões sócio-culturais. ${ }^{11}$ Esta sugestão mereceu o aplauso do antropólogo Malinowski, que, no prólogo ao livro de Ortiz, assim se expressa: "para descrever tal processo [refere-se ao contacto de culturas] o vocábulo formado pelas raizes latinas transculturação proporciona um termo que não contém a implicação de uma certa cultura para a qual tem de tender a outra, senão uma transição entre duas culturas, ambas ativas, ambas contribuintes com aportações e ambas cooperantes no surgimento de uma nova realidade de civilização".

Desta forma se pode observar, como o fez Foster, que a maior parte da cultura hispano-americana e, por extensão, podemos dizer, da cultura ibérico-americana, incluindo em sua apreciação não apenas o caso da colonização espanhola, mas igualmente o da colonização portuguesa, de pequenas comunidades ou de amplitude nacional, constitui uma entidade nova, diferenciada em grande parte de suas raízes originais, sem prejuízo de se conservarem, às vezes nitidamente, as origens respectivas, mas incrustando-se uma na outra: a ibérica na indígena e a indígena na ibérica. ${ }^{12}$

Em meios urbanos, e não apenas em meios rurais, sob a influência de uma cultura popular, o que surgiu foi justamente o resultado desse encontro. Elementos originalmente indígenas se conservam ao lado de elementos primitivamente ibéricos, já não se distinguindo tão nitidamente sua procedência pelo próprio uso decorrente da fusão verificada.

Esta a verdade a que podemos chegar: nesse processo de relacionamento entre grupos diferentes, muito do que a cultura latino-americana hoje apresenta é o resultado da transculturação. Ou seja: de um processo em que os três grupos se interfusionaram e se intermisturaram. O que resultou é o que há de positivamente característico ou típico como uma cultura hoje nossa, peculiar às nossas populações, nitidamente nos meios rurais, embora menos nos meios urbanos, onde outras influências modernizantes ou atuais se fixaram, e ainda se fazem, presentes. O caso, por exemplo, da farmacopéia popular que, originariamente indígena, teve também a participação de elementos africanos, aliás de uma riqueza extraordinária nesse campo, com a aceitação ainda de influências vamos chamar técnicas do ibérico.

É fora de dúvida que o curandeirismo indígena se projetou nas sociedades rurais, incorporando-se aos quadros de sua cultura através de elementos mágicos ou de poderes extranaturais com que procuravam curar males corporais produzidos por agentes externos, ou combater os malefícios de ordem imaterial mediante o uso de força espiritualista. São os chamados feiticeiros de tribos, muitas vezes reunindo em sua pessoa a atividade de 
curandeiro, de sacerdote e de cacique, o que observou Tulio Lopez Ramirez para tribos indígenas venezolanas. ${ }^{13}$ Em outras tribos, na região dos Andes da Venezuela e em outras regiões americanas - registra ainda Ramirez como também outros autores - os três poderes estão separados, exercido cada um por um indivíduo.

A projeção desse curandeirismo difundiu-se através do que poderíamos chamar de uma medicina mágica que revela, de um lado, o poder de uma pessoa como intermediário entre os homens e forças desconhecidas, não raro sobrenaturais, e, de outro lado, a crença que se arraigou na concepção das populações rústicas, não alfabetizadas, e cujo nível cultural não permitiu distinguir bem os valores que estavam em jogo. Exemplo dessa forma de medicina desenvolveu-se através do uso de uma formacopéia rudimentar, à base de vegetais ou de animais da região. É o caso das curas de hemorragia com a colocação de teia de aranha sobre o local; o caso dos preparados de vegetais variados para curar congestões; o caso ainda de benzedores ou rezadeiras, com o uso de folhas de certos vegetais; o caso também, e este bastante difundido, do "curador de cobra"; aplicação de certos líquidos, oriundos de vegetais da região, para curar mordidas de cobras.

A esse curandeirismo indígena veio aliar-se outro; o trazido pelo africano. Medicina indígena e medicina africana juntaram-se e se constituíram fatores para maior fixação no contacto entre os grupos, pois se apresentavam como meios de preservação da saúde ou de cura de enfermos para reintegrá-los no universo social a que pertenciam. Os dois curandeirismos se misturaram, pela própria utilização dos mesmos elementos, animais ou vegetais, de modo a constituírem - é o que registra Gonzalo Aguirre Beltrạn instrumentos de adaptação que reintegram os doentes a seu meio social e cultural. ${ }^{14}$ Medicina que era magia também; medicina mágica que se popularizou no curandeirismo dos meios rurais.

Muitos desses elementos que constituem a base da atividade curandeira do "piache" indígena ou do curandeiro africano ou hoje da rezadeira rural ou ainda dos curandeiros populares, se incorporaram à medicina científica. Vegetais se tornaram fontes de remédios que hoje são usados por médicos, em sua clínica, mesmo em cidades, visto que tais remédios são produzidos cientificamente em laboratórios. A farmacopéia científica se enriqueceu dos valores trazidos da farmacopéia primitiva, que por sua vez se infiltrou e ainda hoje persiste na farmacopéia popular, de meios rurais, não adiantados; o que o antropólogo brasileiro Alceu Maynard Araujo chamou de "medicina rústica". ${ }^{5}$

$\hat{E}$ evidente que o contacto do homem com um meio estabelece uma dialética que leva ao processo de integração em conseqüência da criação do ambiente; este resulta justamente do processo estabelecido: homem e meio se relacionam, e surgem os elementos capazes de fazer com que o homem sobreviva e domine o meio. Não se chega a um extremo do determinismo mesológico; o meio não determina, mas condiciona o comportamento do homem. Este entra com sua criatividade e consegue formar um ambiente adequado.

Foi justamente o que se verificou, no caso dos hoje países chamados latino-americanos, através do encontro dos três grandes grupos que inicialmente ocuparam o seu meio. O dominador - o ibérico - e o trazido como escravo - o africano - ao contacto com o indígena estabeleceram este relacionamento, através do qual foi possível a utilização dos elementos do meio para a criação da sociedade em formação. Mais tarde, já no 
século XIX, a entrada de novos grupos, os trazidos com a imigração, sobretudo imigração de europeus não ibéricos - alemães, italianos, poloneses, por exemplo - também participou desse processo, de modo a poder adaptar-se às condições do ambiente.

De início a utilização, talvez ainda em forma rude, dos materiais mais apropriados ao meio, e nele mesmo encontrados. Era facilmente obtida a madeira nas zonas de florestas, e, em conseqüência, pôde fazer-se a casa com esse material. Se em zonas de palmáceas as palmeiras abundavam, com suas palhas cobriam-se as casas. Se se encontrava facilmente o barro, o uso do adobe se converteu em tarefa comum e constante. Introduziu-se, no caso das zonas tropicais e mesmo em zonas semitropicais, o uso da varanda, em que se armava a rede indígena para as horas de lazer, e que constituía uma proteção contra os efeitos contínuos dos raios solares; e por este motivo o teto inclinado, mesmo sem varanda, mas protegendo as paredes centrais externas da casa.

Da rede - acrescente-se mais esta observação - deve dizer-se que ela não foi apenas usada em horas de lazer. Ao contrário: foi elemento permanente na vivência do homem, tornando-se o leito comum para a vida quotidiana, sobretudo na área amazônica, de onde, aliás, parece ela se ter difundido, alcançando outras áreas americanas. É encontrada em qualquer casa, rica ou pobre, para uso diário, nela dormindo-se nas noites tropicais, tão comodamente como em leito do melhor estilo. O que sucedeu ainda com o uso da esteira, cujo trançado permitiu sua utilização não apenas para colocar as crianças que ainda não andam, mas também para servir de cama ou leito nas casas modestas.

Ainda hoje em zonas pobres, de populações socialmente consideradas de classe inferior, e não apenas em zonas de pescadores, de trabalhadores rurais, etc., é comum encontrar-se o tipo de mocambo com esta característica: o teto inclinado, como uma proteção contra o sol constante. Mesmo nas classes consideradas superiores o tipo de habitação procurou sempre esta adaptação ao meio, o que se poderá verificar na paisagem das casas grandes de engenhos ou de fazendas, em casas urbanas e suburbanas e ainda hoje em certas zonas rurais, mais próximas da zona tropical.

O próprio tipo de casa, em zonas urbanas, usando elementos que o meio oferecia tão facilmente, procurou corresponder a uma identificação de classe. É bem típica a esse respeito a casa urbana, que surgiu no Brasil no período colonial e se estendeu pelo Império, quando justamente se verifica a expansão urbana. Eram as chamadas casas de porta-e-janela, que se alongavam em casas de "bica", de "bica-e-beira", e "de bica-beira-e-sub-beira", exprimindo, nestes termos, o beiral ou beirais existentes - e que eram uma proteção aos raios solares - o apuramento de certa hierarquia social. Daí surgir a expressão de origem portuguesa para identificar pessoa que não possuía bens ou propriedade urbana, não tendo assim uma posição social definida: "homens sem eira, nem beira". ${ }^{16}$

No caso dos edifícios públicos o que se verificou, na América Latina, foi uma transplantação da arquitetura ibérica; portuguesa ou espanhola. Edifícios de órgãos administrativos, Palácios de Vice-reis ou de Governadores, Casas de Câmara ou de Cadeia constituíam, de modo geral, uma imitação do mesmo tipo conhecido ou existente na Península Ibérica. Às vezes isto mesmo se alongava a palácios residenciais, de nobres vindos para a conquista: eram erguidos à imitação de palácios ibéricos. $\mathrm{O}$ que se verificou sobretudo na América de origem hispânica, e, em parte, no Brasil de origem portuguesa. 
O que também se pode observar nesse tipo de construção sobretudo no de áreas urbanas, e, em parte, no de áreas rurais, contudo menos comum - é a presença de traços culturais mouriscos, o que traduz a influência forte e constante desses valores na paisagem ibérica. Em Portugal e na Espanha a influência mourisca foi enorme, ainda hoje testemunhada. Esta influência alongou-se à América ibérica. Traços mouriscos, ou árabes, em geral, aparecem na habitação americana.

Alguns desses traços ainda hoje se conservam na paisagem urbana: a telha mourisca, a janela quadriculada ou em xadrez, a gelosia, o abalcoado, as paredes grossas. Muxarabis e balcões se encontraram - e ainda hoje se encontram em partes do Brasil, do México, do Peru, da Colômbia, por exemplo - tornando nítida essa influência. Só no século XIX os muxarabis passam a ser substituídos pelo vidro, cujo aparecimento, ao que parece, mesmo em cidades européias, somente começa a verificar-se nos fins do século XVIII.

O que Gilberto Freyre observou da presença mourisca no Brasil se pode estender a outras regiões americanas, igualmente influenciadas pelos valores culturais mouros introduzidos por ibéricos ou descendentes de moçárabes ou os próprios mouros.

Seria ainda o caso de discutir-se aqui um outro aspecto de arquitetura e, por extensão, de arte, surgido na América ibérica, com características peculiares em cada uma de suas áreas, através do barroco: o barroco brasileiro ou o barroco espanholizado. São manifestações que exteriorizam não apenas o processo dialético homem $\mathrm{x}$ natureza, mas que se alongam à própria participação dos grupos em contacto. Pois são geralmente artistas mestiços os autores do barroco americano, não raro o indígena ou o africano agindo como artistas da pedra ou do pincel, e assim participando na realização de uma técnica de trabalho trazido pelo europeu, na criação de uma arte que, no Brasil, no México, no Peru, no Equador, por exemplo, se traduziu de maneira regional e característica. Não raro regional e caracteristicamente ecológica. E com uma expressão ecologicamente mestiça.

Esta presença da dialética entre a natureza e o homem se alongou à alimentação, onde os traços culturais de dominadores e dominados se intercruzaram intensamente. Em primeiro lugar, nos primeiros tempos, pela dificuldade de importar os gêneros alimenticios, verificou-se a necessidade de o colonizador adaptar-se desde logo ao uso dos produtos da terra: a mandioca, o milho, as frutas, por exemplo. Nas zonas de rio, ou na beira do mar, a abundância de peixes levou a um uso maior de pescados. $\mathrm{O}$ que ainda hoje marca a paisagem da região amazônica, como um exemplo dessa integração entre a alimentação e a cultura que se formou: o uso de peixes e de tartaruga.

Havia assim uma como que aceitação da vocação da terra, isto é, daquilo que a terra oferecia, de modo a estabelecer-se uma integração mais completa entre o homem e o meio. O caso das atividades e técnicas de alimentação é bem evidente a esse respeito. Em face das dificuldades de obter sua alimentação de base européia nos primeiros tempos, o ibérico foi levado a aceitar a alimentação indígena. Isso, porém, sem prejuízo de importar os gêneros europeus, como o trigo, base de sua alimentação. Embora ambas as soluçōes tenham sicio adotadas - o uso dos produtos da terra e a importação de gêneros - o fato é que a mandioca e o milho se tornaram alimentos comumente aceitos, entrando em rápida circulação no consumo dos colonizadores. Tornaram-se alimento básico na mesa do 
americano, fosse do elemento vindo da Europa, fosse do africano trazido como escravo, fosse do já nascido na terra.

Produtos indígenas passaram a incorporar-se à alimentação através de técnicas não só européias como também africanas; da mandioca ou do milho preparavam-se bolos, grudes, tapiocas, cuscus, mesclando-se os gostos e as técnicas dos três grupos. Quando o europeu introduziu o gado vacum, que não era conhecido na América pré-ibérica, a carne entrou na alimentação; mas seu processo de fabricação sofreu as mesmas inf́luências. Isto é, a técnica indígena foi introduzida no seu preparo; daí o churrasco ou, no caso do Brasil, a carne chamada de sol ou seca. No Nordeste brasileiro a carne é secada ao sol. E completava-se o uso da carne com a farinha de mandioca - esta, indígena, mas já preparada com técnicas européias - e com os feijões, as batatas, os inhames, também indígenas e, em alguns casos, de espécies introduzidas pelo africano.

De fato, no campo da alimentação a contribuição africana se tornou significativa, principalmente através da utilização de produtos por ele introduzidos. No Brasil constituiu-se uma cozinha chamada afro-baiana, que é bem caracteristica da influência africana; e em outras áreas americanas, o elemento africano igualmente fez sentir sua influência, através da introdução de produtos e de técnicas que levaram ao preparo de quitutes onde sua presença era marcante.

Técnicas de origem indígena se infiltraram naquelas que os europeus introduziram. Exemplo bem nítido desse encontro cultural se verificou, por exemplo, nas Missões Jesuísticas; os padres da Companhia de Jesus aproveitaram a estrutura indígena e realizaram uma experiência transculturativa que se sobrepôs ao núcleo originário guarani. ${ }^{17}$ Ao mesmo tempo que se introduziam valores culturais europeus, como a língua, o cristianismo, o vestuário, a organização social, salvaram-se as técnicas de ofícios e artes que eram indígenas, permitindo assim um maior relacionamento com os elementos do próprio meio.

Destas artes e ofícios, ${ }^{18}$ sem dúvida se tornaram mais expressivos os trabalhos de cerâmica, de madeira, de cestaria, de tecidos, criando-se uma como que arte popular que traduzia, de maneira expressiva, o espírito surgido no amálgama entre as tradições ibéricas e as indígenas, mediante o surgimento de novas formas: formas já agora americanas. E não exclusivamente brasileira, ou argentina, ou colombiana, ou uruguaia. Daí o que hoje apresenta a cultura popular latino-americana, através de seus elementos mais característicos, em trabalhos de cerâmica, de palha, de tecidos, traduzindo-se não apenas em formas já hoje tradicionalizadas, mas socialmente representativas do espírito criador do elemento humano que resultou desse processo de mestiçamento, alongado pelos séculos, de relações entre os grupos humanos que aqui se encontraram.

Foi possível assim, no correr dos tempos, pelo ainda pequeno número de séculos de convivência, a criação de mecanismos ou meios que tornaram possivel a integração entre os grupos humanos, fazendo surgir um homem já americano. $\mathrm{O}$ processo dialético entre a natureza e o homem funcionou criativamente. Quer dizer: criou o novo ambiente, deu-the características próprias, e das culturas em contacto no amálgama de seu relacionamento surgiram valores novos. Que são justamente aqueles mais característicos hoje em dia do resultado transculturativo desse processo: $o$ da criatividade cultural do latino-americano de ontem e de hoje. 
Ciência e cultura, no relacionamento que se estabeleceu nos quadros da formação americana, realizaram o que se poderia chamar de domínio da natureza, transformando-a e criando-a de modo a estabelecer um ambiente de vivência para os grupos humanos que aqui se encontraram. As condições naturais encontradas impuseram, de modo particular, a diversidade de aproveit ‘mento desse meio, numa como que atenção à vocação ecológica da terra. Aqui lavoura, ali pesca, mais adiante criação de gado, além extração de vegetais, enfim uma diversificação do quadro natural para a vivência humana.

Isto decorreu da aceitação das técnicas indigenas já experimentadas no meio, de modo a melhor adaptar o elemento chegado de fora. Eram elas, pela experiência do indígena, as únicas possíveis de atender às necessidades de trabalho alienígena. Este trazia outras técnicas nem sempre capazes de corresponder às exigências do meio, e de servir assim à sociedade que se implantava. No trato do solo, por exemplo, o plantio se fazia depois da coivara, segundo a técnica indígena, ainda hoje persistente, em que pesem melhores técnicas introduzidas; sem ela o solo não apresentaria os resultados desejados, ou seja, não teria o rendimento adequado na produtividade. As técnicas indígenas tiveram de ser aceitas e incorporadas pelo colonizador, pelo que representavam como experiência do domínio sobre o meio; com elas foi possível o processo de adaptação e mesmo de integração que permitiu a formação da nova sociedade.

A natureza americana foi apreendida e transformada de conformidade com os recursos que a criação do homem impunha, mas respeit ando sempre o que ecologicamente representava o meio. A imagem da natureza adaptou-se ao concreto de sua exploração; e o homem voltou-se para as práticas que eram possiveis de ser aplicadas, não raro, e isto sobretudo pela influência do indígena, com a utilização de elementos mágicos, que se traduziram, por exemplo, em ritos agrários ou em concepções não menos de espírito criativo, acerca de funções sobrenaturais ou de mitos que se espalharam na paisagem cultural de cada região: mitos da floresta, mitos da água, mitos da mata, mitos das praias, e assim por diante.

À capacidade física do homem sobrepôs-se sua capacidade criadora; funcionou, em termos de criação, sua capacidade mental, desenvolvendo seu potencial de inteligência. Do que resultou, sem dúvida, o quadro cultural latino-americano de hoje: uma paisagem de criatividade cultural onde o pensamento criador do homem se manifesta, seja nas formas materiais de domínio da natureza - técnicas, habitação, vestuário - seja nas concepções espirituais que animam seu mundo mágico - crenças, mitos, supertições, ritos.

Do que até aqui se expôs evidencia-se que a América hoje chamada Latina representa um largo processo de transculturação, cuja principal característica foi aquele resultado que se conceitua como "criatividade cultural". 19 Elementos ibéricos, indígenas e africanos se fusionaram, absorveram elementos de cada um, e chegaram à criação de valores novos. É claro que, em muitos desses valores, ainda se nota a presença do principal elemento originário. O caso da língua: o espanhol ou o português continuam espanhol e português, enriquecidos, porém, de valores novos, palavras, formas semanticas, significados introduzidos pelas línguas indígenas ou africanas. O caso do uso do tabaco: originariamente indígena está hoje usado com o charuto ou o cigarro, que o europeu introduziu. 
Desse processo transculturativo pode observar-se, de um lado, a diferenciação existente internamente nos grupos ibéricos, indígenas e africanos, cada um deles com níveis culturais variados; e, de outro lado, a diferenciação também com que se fixaram na sociedade que então se formava - o espanhol procurando as minas e nelas se estabelecendo, o português voltando às suas origens agrárias, o indígena concentrado em grandes impérios na parte espanhola, disperso, ainda quase nômade, na área portuguesa, o africano introduzindo suas práticas religiosas, seus cantos e danças, embora condicionado por sua situação de escravo. Com a sociedade em formação o português procurou concentrar-se levando o Brasil à unidade, que ainda hoje apresenta, ao passo que o espanhol tendeu à dispersão, dai resultando, com os vice-reinados, a formação de diferentes Estados nacionais no século XIX.

Da influência maior ou menor de cada um dos grupos originários, se chegaria a uma caracterização regional de culturas: aqui, o elemento ibérico preponderando com seus valores; ali, o indígena ainda fazendo ressaltar seus elementos culturais; mais além, o africano com os traços vivos de sua cultura original. A partir da caracterização desses elementos seria possível chegar a uma tipologia de culturas. Ou seja, a América hoje Latina, não uma só cultura, mas elementos culturais identificados em diversos tipos, regionalizados por fatores ecológicos e humanos.

Somos a rigor, do ponto de vista cultural, o que Holmes chamou de "região combinada", no sentido de estar formada por algumas regiōes semelhantes, vizinhas umas das outras; ${ }^{20}$ regiões, entretanto, com valores culturais próprios que a identificam ou caracterizam cada uma em relação a outıas regiões, mesmo vizinhas: a diferença tão sensível entre a região Amazônica e a região Andina, cada uma delas abrangendo diversos países, às vezes os mesmos países, e não apenas fisicamente aproximadas.

"Região combinada", somos principalmente pela circunstância de se preservarem em toda ela valores que se tornaram comuns, embora às vezes diversificados tão só por seu condicionamento ecológico. É a unidade mantida ou preservada pela diversidade; esta diversidade, não raro contrastante, criou um equilíbrio que assegurou a unidade. ${ }^{21}$ Daí a importância que tem, na fixação de uma tipologia cultural para a América hoje chamada Latina, o relacionamento entre o meio ocupado, o grupo humano que o ocupou e a atividade que aí se implantou, considerando, principalmente, a estrutura das sociedades que se encontraram e o tempo histórico do processo em sua evolução.

Seria este talvez o elemento fundamental para uma caracterização tipológica de cultura: o processo de ocupação humana. O que foi encontrado na terra, como o homem ocupou esta terra, e que atendimento deu à vocação ecológica desta mesma terra seriam, cremos, os elementos constitutivos de uma formulação teórica capaz de permitir a formação de uma tipologia cultural, quer para a América Latina, quer para outras regiōes do mundo. Somente assim se poderia chegar a um estudo comparativo, a partir, portanto, de uma base comum na tipologia de culturas.

Nossas populações mestiçadas no relacionamento físico entre os grupos humanos formaram uma cultura também mestiça, em pleno processamento, muitas vezes ainda hoje sem se definir com precisão, mas procurando a realidade desse mestiçamento. Há a considerar também que este mestiçamento, tanto o físico como o cultural, decorreu em meio tropical, ou às vezes semitropical, mas preponderantemente sob a influência 
tropical. Pois em zona predominantemente tropical - Guatemala, México, Andes - os espanhóis encontraram os mais adiantados grupos indigenas. Em pleno trópico, principalmente no Nordeste, no Oeste, na Amazônia, com o sertanismo nordestino e o bandeirismo paulista, e em parte também no Sul, não inteiramente tropical, mas sem dúvida com condições próximas ao trópico, desenvolveram-se também as relações humanas e culturais do grupo português com os indígenas no Brasil; e igualmente com os africanos trazidos como escravos, procedentes, da mesma forma, de zonas tropicais. Regiões aquelas - do Nordeste, do Oeste, da Amazônia - onde ainda hoje se estabelecem tais contactos.

A variedade da mestiçagem cultural, diversificada pela maior influência aqui ou ali de um dos grupos, resultou, de modo fundamental, do ambiente criado; aptidões e técnicas na atividade implantada em relação às condições que o meio oferecia, se constituíram os principais elementos nos contactos estabelecidos, gerando daí aspectos peculiares, não raro identificados pela influência que o meio proporcionava. Se isto se verificou nos primeiros tempos, com a primitiva implantação colonizadora, verificou-se igualmente mais tarde, com a expansão da ocupação humana, esta já realizada pelos próprios filhos da terra. A tipologia cultural que poderemos encontrar é basicamente a que resulta desse contacto humano em sua relação com o meio: uma tipologia culturalmente ecológica.

\section{Departamento de Sociologia}

Pontifícia Universidade Católica

Rio de Janeiro - BRASIL 


\section{NOTAS}

${ }^{1}$ HENRIQUEZ UREÑA, Pedro. Historia de la Cultura en la América. México, Fondo de Cultura Económica, 1949. (Col. Tierra Firme), especialmente p.11. Sobre as populações indígenas nas Américas é grande a bibliografia. Quanto a seus níveis de cultura, ver também SCHMIDT, Wilhelm. Etnologia Sul Americana. Círculos culturais e estratos culturais na América do Sul. Trad. Sergio Buarque de Holanda. São Paulo, Companhia Editora Nacional, 1942. (Col. Brasiliana, 218).

${ }^{2}$ Sobre os espanhóis, ver CARO BAROJA, Julio. Los pueblos de España. Ensayo de Etnología. Barcelona, Editorial Barma S.A., 1946; especialmente a terceira parte - cap. XI a XIX. Sobre Portugal, em particular, DIAS, Jorge. "Algumas considerações sobre áreas culturais. A área cultural luso-brasileira"; e "Os elementos fundamenta is da cultura portuguesa". In: Ensaios Etnologicos. Lisboa, 1961. (Estudos de Ciências Políticas e Sociais, (52). p. 73-80; 97-120; e também RIBEIRO, Orlando. Portugal, o Mediterrâneo e o Atlântico. Coimbra, Co imbra Editora Limitada, 1945. (Col. Univer sitas).

${ }^{3}$ Sobre o africano no Novo Mundo, ver principalmente, SACO, José Antonio. Historia de la esclavitud de la raza africana en el Nuevo Mundo y en especial en los países americo-hispánicos. La Habana, Cultural S.A., 1938. 4v. (Col. Livros Cubanos); RAMOS, Arthur. As culturas negras no Novo Mundo. 2.ed. São Paulo, Companhia Editora Nacional, 1946. (Col. Brasiliana, 249); ORTIZ, Fernando. Los negros esclavos. La Habana, Revista Bimestre Cubana, 1916. (Hampa Afro-Cubana); BASTIDE, Roger. Les Ameriques Noires; les civilisations africaines dans le Nouveau Monde. Paris, Payot, 1957. Há ainda estudos sobre o negro em capítulos de livros sobre países da região. Bibliografia bastante vasta encontra-se em INFLUÊNCIAS Africanas na América Latina (Fontes Bibliográficas). Rio de Janeiro, Centro Latino-americano de Pesquisas em Ciências Sociais, 1963. (Mimeogr.)

${ }^{4}$ Para a data da introdução do africano na América, ver SACO, José Antonio, op. cit.; e ORTIZ, Fernando, op. cit.

${ }^{5}$ FREYRE, Gilberto. Casa Grande \& Senzala. 5.ed. Rio de Janeiro, Livraria José Olympio Editora, 1946. v.1, p. 214.

${ }^{6}$ FROBENIUS, Leo. Histoire de la Civilisation Africaine. $12{ }^{\text {ème }}$ ed. Trad. par Dr. H. Back et D. Ermont. Paris, Gallimard, s.d.; ver também BAUMANN, M. \& WESTERMANN, D. Les peuples et les civilisations de l'Afrique. Paris, Pa yot, 1948. Ver ainda MAQUET, Jacques. Les civilisations noires. Paris, Marabout Université, 1966; e vasta bibliografia especializada no estudo de diferentes aspectos das culturas africanas.

${ }^{7}$ SANCHEZ, Luiz Alberto. Existe América Latina? México, Fo ndo de Cultura Económica, 1945. p. 142.

${ }^{8}$ RIBEIRO, Orlando. Op. cit., p. 174 e seguintes; RIBEIRO, Orlando. Aspectos e Problemas da Expansâo Portuguesa. Lisboa, 1962. p. 28. (Estudos de Ciências Políticas e Socia is, 59).

${ }^{9}$ Sobre o curare ver o estado atual de seus estudos em CARNEIRO, Paulo - Des faits nouveau sur le curare et la curarisation. In: Vers un nouvel humanisme. Paris, Seghers, 1970; sobre o preparo ver sua descrição em SALAS, Julio C. Etnología e Historia de Tierra Firme, (Venezuela y Colombia). Madrid, Editorial America, s.d. p. 54 e seguintes. 
${ }^{10}$ L.A. Sancher refere que efeitos do primeiro choque resultaram mortíferos para os índios em Existe América Latina? cit., p.80.

${ }^{1}$ ORTIZ, Fernando. Contrapunteo Cubano del Tabaco y el Azucar. La Habana, Jesus Montero Editor, 1940. Prólogo, p. XVII.

12 FOSTER, George. Cultura y Conquista: la herencia española de América. Xalapa, México, Universidad Veracruzana, 1962. p. 25.

${ }^{13}$ LOPEZ RAMIREZ, Tulio. Apuntes sobre el piache indígena venezolano. Acta Americana, México, 2(1/2) 70, jan. 1944.

14 AGUIRRE BELTRAN, Gonzalo. Medicina e Magia. México, Inst ituto Nacional Ind igenista, 1963. p. 258. (Col. de Antropologia Social).

15 ARAUJO, Alceu Maynard. Medicina Rústica. São Paulo, Companhia Editora Nacional, 1961. (Col. Brasiliana, 300). Sobre a med icina popular a bibliografia brasileira é mu ito rica.

${ }^{16}$ DIÉGUES JÚNIOR, Manuel. Etnias e Culturas no Brasil. 6.ed. Rio de Janeiro, Ed. Civilização Brasileira, 1977. Sobre tipos de arquitetura no Brasil, "er também: id. - O Brasil e os Brasileiros (Ensaios sobre alguns aspectos das características humanas das populações brasileiras). São Paulo, Livraria Martins Ed itora, 1964.

17 BAGU, Sergio. Economía de la Sociedad Colonial (Ensayo de Historia Comparada de América Latina). Buenos Aires, Librería El Ateneo Editorial, 1949. p. 63.

${ }^{18}$ Sobre artes e ofícios na colonização americana, ver FOSTER, George, op. cit.

19 O conceito de "criatividade cultural" foi formulado pelo Seminário Inter-Univer sitário de Verão sobre Aculturação em 1953: ACCULTURATION: an exploratory formulation. American Anthropologist, Andover, Mass., 56(6) 973/1000, Dec. 1954.

${ }^{20}$ HOLMES, J. Macdonald. The Geographical Basis on Government; specially apllied eto New South Wales, apud KING, H.W. The Pattern of Human Activities. Sidney, Modern Regional Australiasian Publishing Company, 1952. p. 21. Ainda sobre áreas culturais, no que se refere à sua formulação teórica, ver KROEBER, A.L. Cultural and Natural Arsas of Native North America. Los Angeles, Cal., University of California Press, 1953; e sobre problemas ecológicos, em particular na caracterização de áreas ou regiôes, ver COLLOQUES Internationaux du Centre National de la Recherche Scientifique Les Divisions Ecologiques du Monde. Paris, Centre National de la Recherche Scient if ique, juin/juil. 1954.

${ }^{21}$ Sobre diversidade da América Latina, ver DIÉGUES JÚNIOR, Manuel. Introducción a la Sociología Regional. México, Universidad Nacional, 1954. p. 69 e seguintes. (Cuadernos de Sociología). 